DOI: $10.20472 /$ IAC.2020.056.005

\title{
WEIHANG HUANG
}

The Chinese University of Hong Kong, China

\section{RE-INVESTIGATING ENGLISH ORIGINS OF NEW ZEALAND ENGLISH VIA PHYLOGENETIC RECONSTRUCTION}

\begin{abstract}
:
New Zealand English is one of the newest English variants among native English speakers in New Zealand. However, details of its origins remains under debate, despite the consensus on Maori influence and the global picture of its history, and two questions are long-unsolved: what English variant(s) contribute(s) to the origin(s) of New Zealand English, and where New Zealand English is on the family tree of English variant. On these questions, previous studies give two different hypotheses, namely "single-origin" and "mixing-bowl", neither of which however, is decisive. In this study, this two questions are re-investigated via phylogenetic reconstruction of English variants. By using data collected from Accents of English from Around the World database and Sound Comparisons, the phylogenetic tree of English dialects is constructed via Lingpy. The results shows that New Zealand English is exceptionally likely to be a "mixing-bowl," where Scottish English and American English and even South African English are among major contributors.
\end{abstract}

\section{Keywords:}

New Zealand English, language variant, phylogenetic reconstruction 


\section{Introduction}

New Zealand English (NZE) is an English language variant in both spoken and written modality among people in New Zealand whose native language is English (Hay, Maclagan and Gordon, 2008). Despite debates upon its origins and features and the similarity between New Zealand English and standard dialect of English or other English variants like Australian English (Bauer, 2011), there is almost no doubt that New Zealand English stands as a new English variant since New Zealand English owns vital differences in the aspects of phonology (Bauer, 1986) and vocabulary (Deverson, 1991). However, unlike other English variants, New Zealand English is considered one of the newest English variants for the history of New Zealand English merely spans across around one and half of a century since the English colonists arrived in New Zealand in the 19th century, bringing with them English (Trudgill et al., 2000). As an emerging variant, New Zealand English has much of its puzzle unsolved and under debate, among which are the details on the origins of New Zealand English.

On this topic, there are two agreements upon the global picture. On the one hand, English colonists brought English to New Zealand, and from then on New Zealand, English gradually develops, incorporating features from English variants as well as other languages like Maori (Deverson, 1991); and finally, New Zealand English ends up in having its distinctive linguistics feature to be a brand new English variant (Trudgill et al., 2000). On the other hand, Maori is considered to influence New Zealand English, especially on the facet of vocabulary borrowing (Deverson, 1991; Daly, 2007). Even though Maori's influence upon New Zealand English is undeniable, Maori cannot stands as the origin of New Zealand English since it is distinctively different from English in phonology, vocabulary, and syntax (Harlow, 2007).

However, there is no consensus upon the relationship between New Zealand English and other variants of the English language. On this topic, there are two problems long-unsolved: what English variant(s) contribute(s) to the origin(s) of New Zealand English, and where New Zealand English is on the family tree of English variant. Currently, there are two significant groups of hypotheses, single-origin, and "mixing-bowl" origin (Gordon et al., 2004; Bauer, 2011; Bergs and Brinton, 2017).

In single origin hypotheses, New Zealand English is considered to originate from only one English variant, though what is the variant is under within-group debate. These are English variants that are considered to be possible English origin: southern England English(including Cockney), and Australian English (Bauer, 2011).

Hypotheses that support southern England English as the origin of New Zealand English are put forward since southern England English, for example, the Cockney accent, is similar with New Zealand English in the aspects of phonological features like rhyming and vowel sound (Bauer, 2011), or even thought to share "identical" pronunciation with New Zealand English by some people in the United Kingdom (Gordon et al., 2004). Meanwhile, the evidence is also found in the vocabulary that vernacular London English share some rhyming slang with New Zealand English, for example, "have a butcher's" for "let me have a look" (Bauer, 2011). However, "being similar" or even "being identical for some people" is not the same as "being identical," especially in some 
rhyming patterns like off-dwarf rhyming pairs. Therefore, it is hard to claim that southern England English is the sole origin of New Zealand English (Gordon et al., 2004; Bauer, 2011).

Meanwhile, the Australian English hypothesis comes into being for a similar reason: the considerable resemblance between Australian English and New Zealand English (Bauer, 2011). Furthermore, there is a strong version of this hypothesis that New Zealand English is just derived from Australian English (Hundt, 2017). The similarity between Australian English and New Zealand English is of high prevalence: Both Australian English and New Zealand English are nonrhotic dialects (Bauer et al., 2007), while in vocabulary, there are words that are shared only by Australian English and New Zealand English, like the greeting world "coo-ee" (Bauer, 2011). Furthermore, there is also evidence in the demographic aspect that trade routes connect New Zealand and Sydney, Australia (Bauer, 2011). Thus, it seems reasonable to take Australian English as the origin of New Zealand English. However, this group of hypotheses is challenged: the potential origin of Australian English is also southern England English, and indeed Australian English shares its linguistic features with southern England English variants just like what New Zealand does (Gordon et al., 2004; Bauer, 2011; Hundt, 2017). Therefore, it is difficult to rule out the hypotheses in the previous group, where the southern English dialect is taken as the origin of New Zealand English. As a result, this group of hypotheses faces the same problem with the previous group: whether Australian English is the only origin, and this problem is actually difficult, and end up in either debate or even change of proposed hypotheses for some scholar (Bauer, 1997; Gordon et al., 2004; Hundt, 2017).

Since the common problem faced by single-origin hypotheses is tough, while it is a hard fact that New Zealand English is influenced by several English variants (Gordon et al., 2004; Hundt, 2017; Nelson et al., 2020), the "mixed-bowl" hypothesis is put forward, where New Zealand English is considered to develop independently despite being influenced from multiple external English variants, and also a non-English variant of Maori which has been taken as a consensus (Gordon and Deverson, 1998). This hypothesis seems to be widely accepted since it overcomes the problem shared by single-origin hypotheses. However, the problem of New Zealand English origin remains, since what is the recipe of "mixing-bowl" is still unclear. In fact, the old mystery of where New Zealand English is born escalates into under what influence New Zealand English is influenced. In this case, despite the contradiction between "mixing-bowl" hypotheses and singleorigin hypotheses, the proposed single origin are transformed into a potential source of influence on New Zealand English (Bauer, 1999, 2011), while those English variants that are once thought to be impossible to be the origin of New Zealand English, now join potential source of influence as well, including Scottish English (Bauer, 1997; Trudgill, MaClagan and Lewis, 2003), Irish English as well as the American English since a potential Americanization is taking place in New Zealand English (Hundt, 2017) Meanwhile, despite the lack of research, English in Africa and Asia would potentially put an influence on New Zealand English as New Zealand English is changing (Görlach and Schneider, 1997; Gordon et al., 2004; Hundt, 2017).

In spite of the availability of these hypotheses, the origin of New Zealand English remains a question no matter which group of hypotheses is under examination: for single-origin hypotheses, the common flaw is that they cannot rule out their peers to make them "single" in origin, while for the "mixing-bowl" hypotheses, original problem escalates into what language influence New Zealand English. Consequently, it seems that the prolonged debate on the origin of New Zealand 
English comes to a tie. Nevertheless, through the debate third consensus surfaces, in addition to English origin and Maori influence, and this consensus is in methodology: English variants that have more similarity with New Zealand English in linguistic features tend to be considered as the origins of New Zealand English, which is the principle of phylogenetic reconstruction. By measuring "language distance," which can represent the relationship between two languages (List et al., 2018), phylogenetic reconstruction is able to demonstrate and quantify the relationship among languages (List, 2016; List et al., 2018). Moreover, this method turns out to be effective and successful in seeking the potential origin of a language (Zhang et al., 2019), or just like in this research, seeking the phylogenetic position of a language variant in several language variants belonging to a common language (List et al., 2014). Therefore, via phylogenetic reconstruction, new insights may be found in the origin of New Zealand English. Thus, in this study, attempts are made to re-investigate potential origins among English dialects and find out which hypotheses are most likely via phylogenetic reconstruction.

\section{Methodology}

\subsection{Data Collection}

To reconstruct the phylogenetic tree of available English variants, words that represent the fundamental concepts of the language variants shall be first collected and then prepossessed into a list of word-concept pairs. Furthermore, to make feasible collecting these words in all language variants, the selected concepts are required to be pervasive in all targeting language variants. Traditionally, Swadesh's 100-word list should be adopted since it is robust in successfully representing the critical feature of languages, and the concepts inside are carefully selected so that almost every language has words denoting them (Swadesh, 2006). However, the availability of words denoting these concepts does not guarantee that these word-concept pairs with precise phonological and orthographic transcription are easily accessible, potentially hampering the feasibility of the research. Unfortunately, this is what this study is facing. Therefore, this research needs to find other accessible alternatives.

Nevertheless, the rule of selecting concepts in the Swadesh list does set the criteria for selecting a new option. The new option should fulfill (1) able to represent the key concepts in targeting English variants, and (2) each critical concepts in (1) shall be denoted by at least one word in each targeting English variants, and the word should come with precise phonological and orthographic transcription (Swadesh, 2006). Furthermore, (3) a collection of concept-word pairs intended for cognate-based analysis is preferred, since automatic cognate detection is the precursor step of phylogenetic reconstruction in this study, and (4) the collection need to cover at least an English variant from these regions: New Zealand, Australian, Southern England, Scotland, and North America so that both groups of hypotheses can be examined.

Fortunately, two data sets fulfill all of the three requirements: Accents of English from Around the World database and Sound Comparisons. Both Accents of English from Around the World and Sound Comparisons are online databases that are created for providing representing impression on English variants, which suits requirements (1). Besides, both databases own the precise phonological and orthographic transcription for 110 concepts for most of the variants covered, which fulfill the requirement (2) after excluding those variants which do not have phonological or 
orthographic transcriptions for all 110 concepts. Besides, these two data sets are intended for cognate-based analysis, which fits the requirement (3). Finally, a combination of the two data sets covers the English variants required in (4) (Heggarty, Maguire and McMahon, 2008; Maguire and Heggarty, 2019).

Therefore, a combination Accents of English from Around the World database and Sound Comparisons is taken as the source of data for phylogenetic analysis. Concept-word pairs are retrieved from the section of Engl. \& Wales: S/M, England: North, Scotland \& Ireland, North America and Rest of the World on Accents of English from Around the World and Sound Comparisons (Heggarty, Maguire and McMahon, 2008; Maguire and Heggarty, 2019).

After that, concept-word pairs are checked for integrity and preciseness of their corresponding phonological and orthographic transcription. An English variant is removed if it has missing phonological transcription or orthographic transcription of the word corresponding to that 110 concepts. Then, for any English variant that can be further divided into sub-variants, like Tyneside, sub-variants marked "typical" and "traditional" is taken, while the other sub-variants are excluded due to the SANE rule (List et al., 2018).

After this, the remaining English variants, together with concept-word pairs, are combined and formatted into a word list that is readable by lingby (List et al., 2018). The list of English variants taken is shown in appendices as Table 1, while their geographical location is shown in Chart 1, where the list of 110 concepts is provided in Table 2 as well. Besides, in the list of English variants, the type of English variant is also given, where the whole entry of the English variant is color-coded accordingly. Among the taken English variants, New_Zealand_Auckland_typ represents New Zealand English.

Table 1: Languages for Test

\begin{tabular}{ll}
\hline Language Code & Category \\
\hline Buxton_typ & English in England: North \\
Cornhill_typ & English in England: North \\
Tyneside_typ & English in England: North \\
Rossendale_typ & English in England: North \\
Holy_Island_trad & English in England: North \\
Tyneside_trad & English in England: North \\
Middlesbrough_typ & English in England: North \\
Liverpool_typ & English in England: North \\
Berwick_typ & English in England: North \\
Longtown_typ & English in England: North \\
London_trad & English in England. \& Wales \\
North_Devon_typ & English in England. \& Wales \\
S_Wales_Rhymney_typ & English in England. \& Wales \\
RP & English in England. \& Wales \\
Norwich_typ & English in England. \& Wales \\
North_Devon_trad & English in England. \& Wales
\end{tabular}




\begin{tabular}{|c|c|}
\hline Belfast_typ & English in Ireland \\
\hline Antrim_trad & English in Ireland \\
\hline Tyrone_trad & English in Ireland \\
\hline Antrim_typ & English in Ireland \\
\hline Galway_Loughrea & English in Ireland \\
\hline Buckie_trad & English in Scotland \\
\hline Standard_Scottish & English in Scotland \\
\hline Edinburgh_trad & English in Scotland \\
\hline Edinburgh_typ & English in Scotland \\
\hline Lewis_typ & English in Scotland \\
\hline Coldstream_typ & English in Scotland \\
\hline New_York City_trad & English in North America \\
\hline Standard_Canadian & English in North America \\
\hline Boston_trad & English in North America \\
\hline Chicago_typ & English in North America \\
\hline Ohio_typ & English in North America \\
\hline Standard_American & English in North America \\
\hline Alabama_trad & English in North America \\
\hline N_Carolina_trad & English in North America \\
\hline Nigeria_typ_native_Igbo_speaker & English in Aftica \\
\hline South_Africa_Johannesburg_typ & English in Aftica \\
\hline Singapore_std & English in Asia \\
\hline India_New Delhi_std & English in Asia \\
\hline Australia_Perth_typ & Australian English \\
\hline New_Zealand_Auckland_typ & New Zealand English \\
\hline
\end{tabular}

Source: Self-compiled, using data from Accents of English from Around the World and Sound Comparisons

Table 2: Concept Involved in Word List Compiling

\begin{tabular}{lllllllll}
\hline \multicolumn{7}{c}{ Concepts Involved } \\
\hline all & six & leaf & heart & moon & stone & mid & full & calf \\
fight! & wind & over & mouse & ring & yard & red & horn & green \\
ice & eat! & three & see! & top & fast & tongue & earth & name \\
oak & hound & bone & warm & cow & hunger & cold & what? & hundred \\
swear! & needle & good & day & hear! & nine & hand & bite! & night \\
ash & snow & liver & holy & mother & stool & milk & thing & four \\
fish & wool & quick & mouth & salt & year & right & honey & open \\
in & eight & thunder & seven & two & father & tooth & naked & ten \\
one & house & brother & wash! & daughter & I & corn & sit! & better
\end{tabular}




\begin{tabular}{lllllllll} 
tear & new & goose & drink! & lamb & north & head & white & young \\
bath & sore & long & home & oven & storm & ear & knee & foot \\
five & word & rain & nail & thorn & toe & sharp & out & blood \\
is & eye & & & & & & & \\
\hline
\end{tabular}

Source: Self-compiled, using data from Accents of English from Around the World and Sound Comparisons

\section{Chart 1: Distribution of English Variants Involved: Overview}

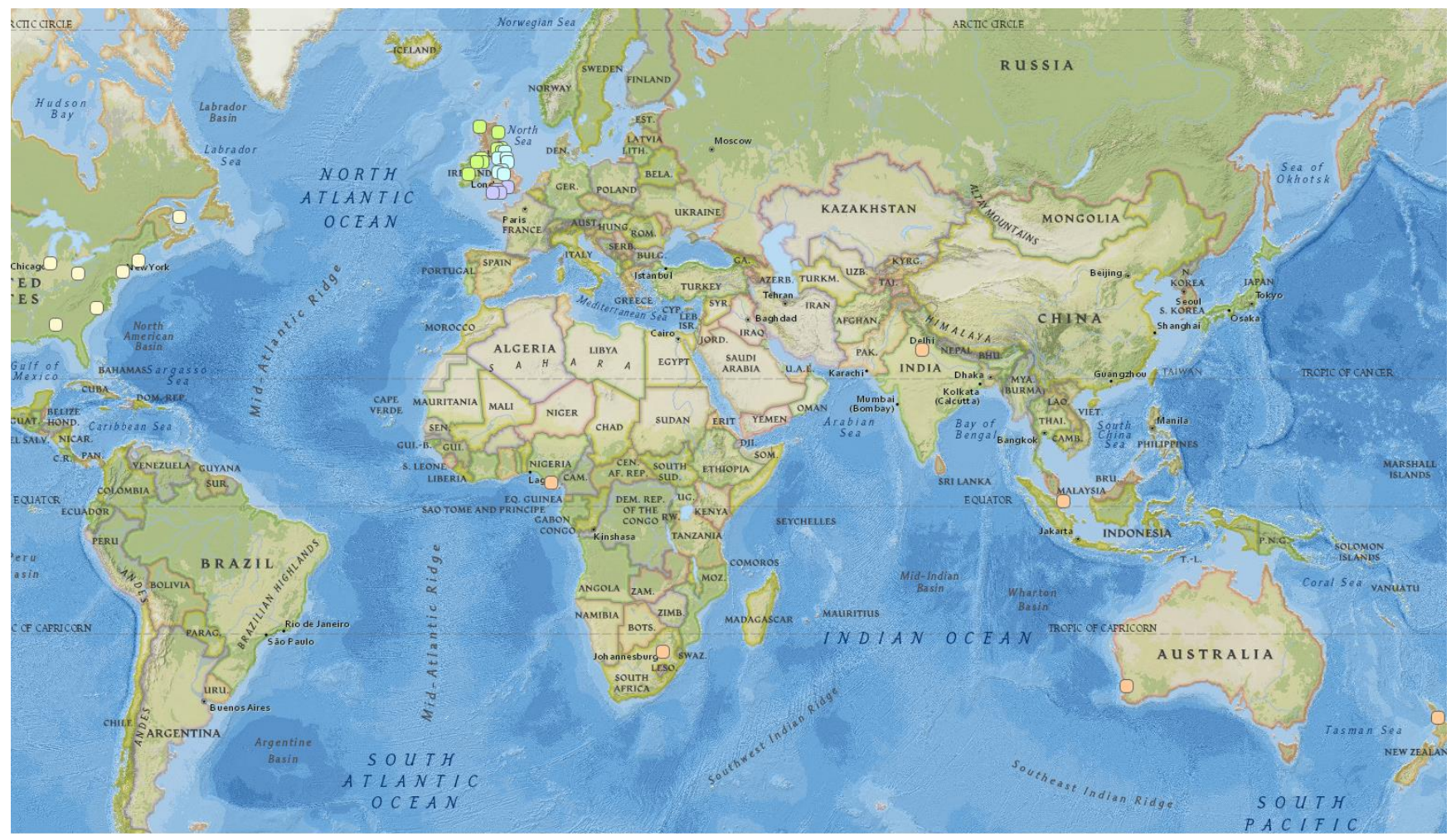

Source: Self-compiled, using data from Accents of English from Around the World and Sound Comparisons

\subsection{Phylogenetic Reconstruction}

Phylogenetic reconstruction start after the lingpy readable word list is ready. This study adopts the python package called lingpy, a python module for automatic cognate detection language distance analysis and phylogenetic tree visualization and reconstruction (List et al., 2018, 2019).

In order to model the English variants via phylogenetic reconstruction, automatic cognate detection is performed as the first step by using the class lingpy.compare.lexstat. LexStat, and then the function LexStat.get_distances() is used to calculate the language distance of every pair of English variants. The next step is to use lingpy.neighbor() so that the phylogenetic tree of these English variants is generated. All of these functions are called with default parameters. In the end, the phylogenetic tree is depicted in asciiArt for further analysis.

\section{Result and Analysis}

With the help of lingpy module, a phylogenetic tree of English dialect is reconstructed, which is shown in Chart 2. 


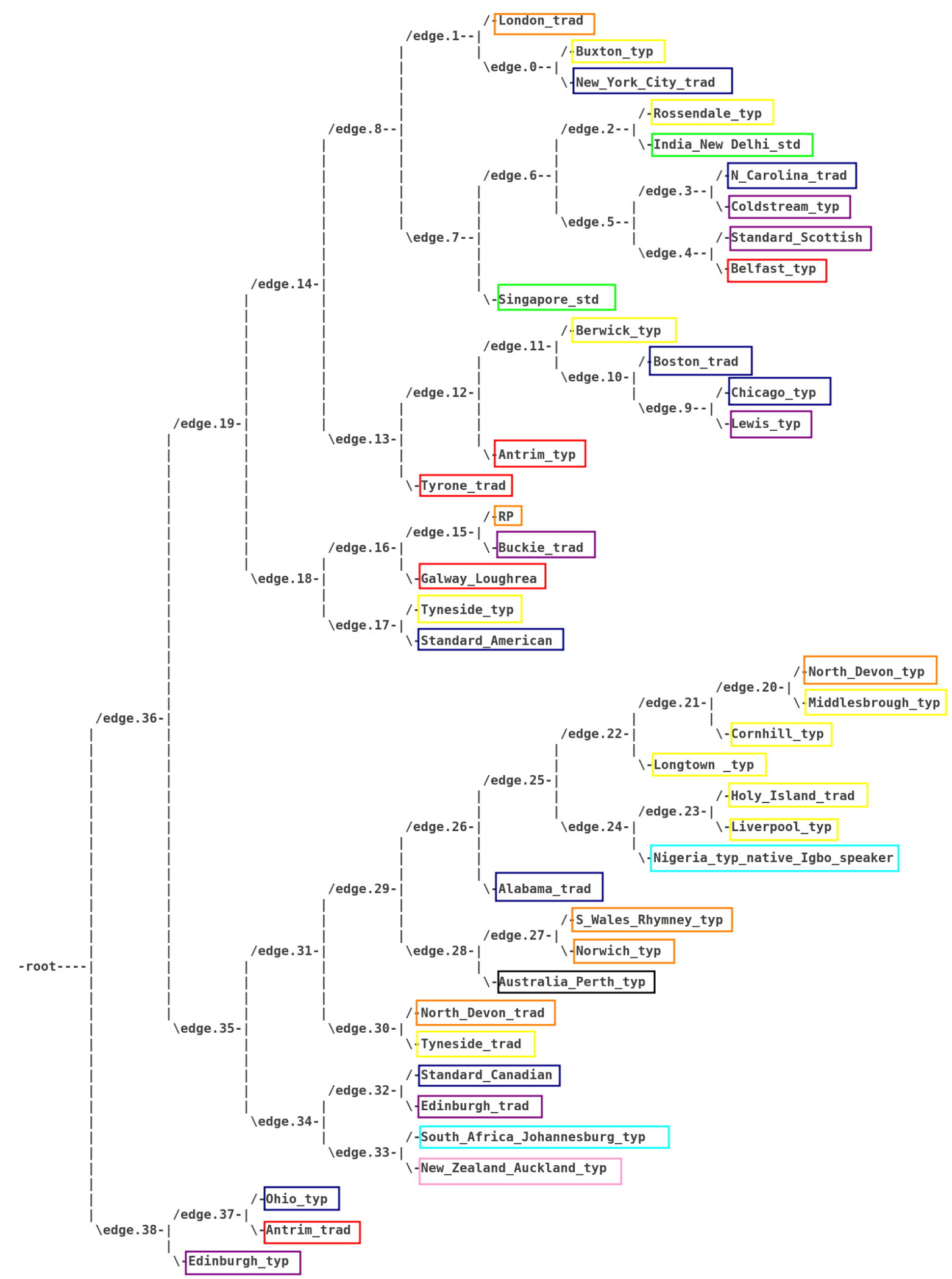

Chart 2: Phylogenetic Tree of English Variants and the Position of New Zealand English Source: Self-compiled via Lingpy by using data from Accents of English from Around the World and Sound Comparisons 
In this chart, the position of New Zealand English on the family tree of English variants is shown. In the tree, New_Zealand_Auckland_typ represents New Zealand English. Its only sister node, namely South_Africa_Johannesburg_typ, is one of African English variants. The mother node for both New_Zealand_Auckland_typ and South_Africa_Johannesburg_typ is neighbor to the shared mother node for Standard_Canadian, an American English variant, and Edinburgh_trad, an Scottish English variant. Meanwhile, compared with previous nodes, the node represents New Zealand English is far away from that representing an Australian English variant, namely Australia_Perth_typ, as well as southern England English variants, among which the Tyneside_trad is the nearest.

Therefore, New Zealand English seems to have a mixed origin since New Zealand English is closely related to several English variants, which are from different groups of English variants, like Scottish English group, North American English group, or even African English group. The hypotheses of single-origin are rejected, especially for those hypotheses claim that the origin New Zealand English is Australian English or within southern England English group, since both Australian English as well as any variant in southern England English group are less related to New Zealand English in comparison.

Then as mentioned above, the question on the origin of New Zealand English escalates into what variants influence New Zealand English, as these variants contribute to the independent development of New Zealand English. The significant influence from Scottish English is actually expected in the previous literature: similarity is shared between New Zealand English and Scottish English, including the population feature and some phonological features like central [I] (Bauer, 1997). Meanwhile, it is also expected to find Canadian English closely related to New Zealand English, since an ongoing Americanization is already suspected by literature (Hay, Maclagan and Gordon, 2008; Hundt, 2017). However, it is surprising to find a significant relationship between New Zealand English and South African English in Johannesburg, though previous studies usually ignore the influence of English variants in Asia and Africa. However, the result shows that these English variants should not be neglected but incorporated in research since some variants may have a significant influence on New Zealand English, even though they may not be the sole origin. The influence from South Africa on New Zealand English is echoed by the distribution of historical trade routes where South Africa is linked with New Zealand with a major trade route, which would provide an environment for language contact (Trade route chart of the British Empire, 1932).In the meantime, with a further check of this map of trade routes, the answer to why these three groups of English variants are closely related to New Zealand English surfaces: all of these three groups of languages are on a major trade route from Scotland, to Canada, to South Africa and finally to New Zealand as shown in Chart 3. Thus, it is quite convincing that South African English influences New Zealand English, meaning that South African English contributes to the recipe of "mixing-bowl," which is the answer to the question: what is the origin of New Zealand English. 


\section{Chart 3: Trade Route of the British Empire in 1932}

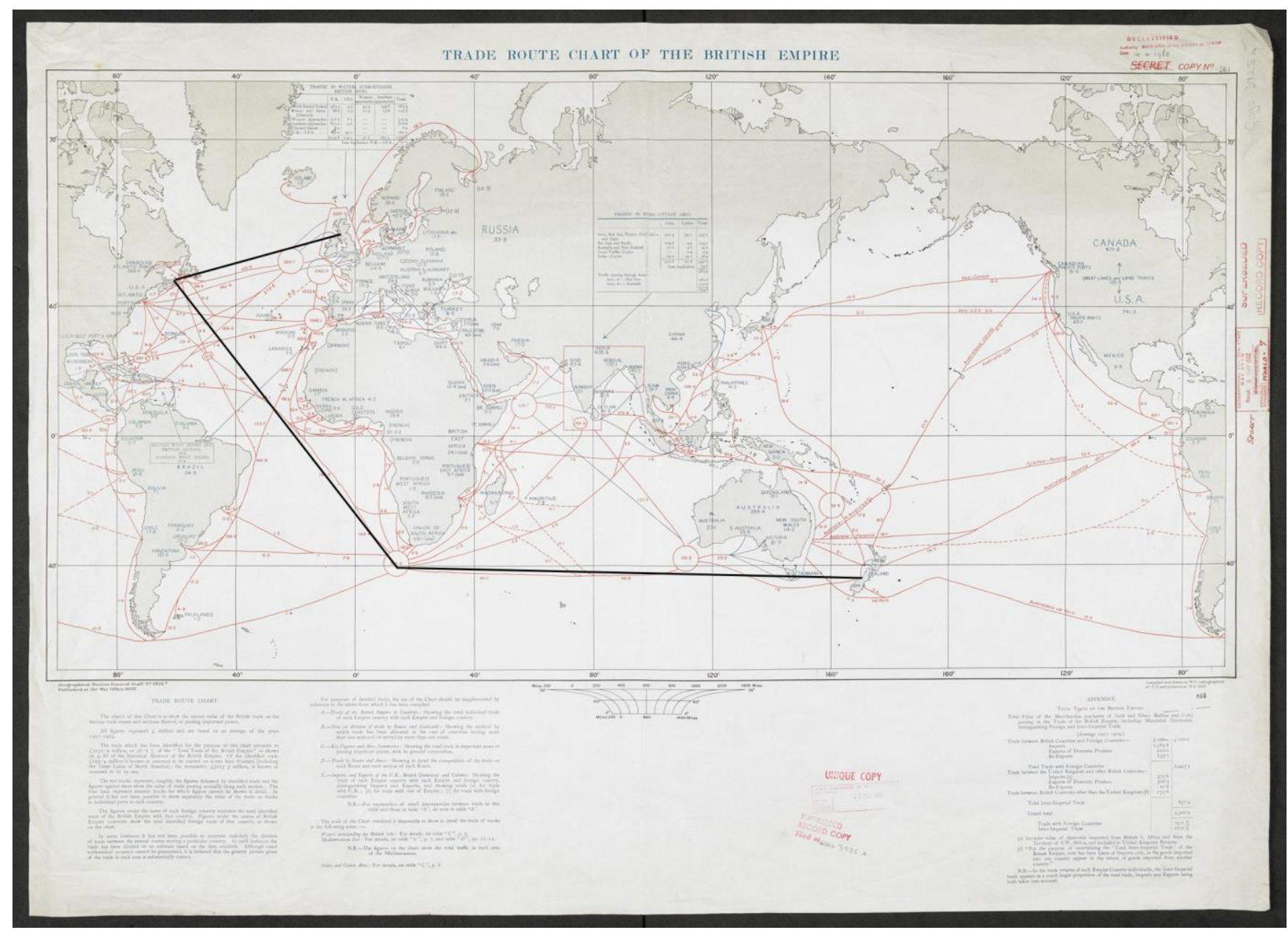

Source: Own adjustment based on "Trade route chart of the British Empire" at https://www.bl.uk/collectionitems/trade-route-chart-of-the-british-empire

\section{Discussion}

So far, the phylogenetic tree is generated, and according to the tree, "mixing-bowl" hypotheses are supported. As for the English variants that influence New Zealand English, these English language variants are among the top contributing English variants towards the linguistic features of New Zealand English: Scottish English varieties represented by English variant in Edinburgh, North American English variant, especially Canadian English, and African English represented by South_Africa_Johannesburg_typ. However, New Zealand English is one of the newest English variants, which is still developing. As new language contacts are made, new influence will be almost for certain induced. Therefore to be more accurate, the New Zealand English mentioned in this paper refers to the state of this variant in the second decade of the 21 st century, and it is highly recommended that this research be replicated after a few decades to see whether there are new languages that impose new significant influence upon New Zealand English. 
Besides, further improvements can be made via replicating this research upon different data sets, especially Swadesh's list, which is typical for seeking the origin of a language or language variant (Swadesh, 2006; Zhang et al., 2019). Therefore, this research can be improved by replicating the method on various data set and concept lists, especially the Swadesh's list.

Moreover, as an extension of the previous improvement, all possible methods of phylogenetic reconstruction with all possible parameters can be performed on the data sets mentioned above in order to improve the robustness and credibility of the result. Since phylogenetic reconstruction is based on computer programs that inevitably introduce error (Juola, 2006), using multiple methods will different parameters would help mitigate harm from potential machine error. In the meantime, as the lingpy is reported to be conservative in automatic cognate detection, which is the previous step of phylogenetic reconstruction (List et al., 2018). more methods can be applied to examine the current result.

\section{Conclusion}

Phylogenetic reconstruction reveals that the origin of New Zealand English is exceptionally likely to be a "mixing-bowl," where the single-origin hypotheses are rejected. Then on the escalated question, namely what is in the mixing bowl of New Zealand English, this result echoed the previous literature on that Scottish English and American English are contributors of nowadays New Zealand English. Meanwhile, South African English is indicated to contribute to New Zealand English as well. As a vigorously developing English variant, New Zealand English has been influenced by a number of language in the past and present, which leaves a trace on its linguistics feature, and it is interesting to see what English variant will be the next in joining the contributors of New Zealand English in the future, where it is the best that every variant is taken into consideration, and nothing shall be neglected again.

\section{$6 \quad$ Reference}

Bauer, L. (1986) 'Notes on New Zealand English Phonetics and Phonology', English World-Wide, 7(2), pp. 225-258. doi: 10.1075/eww.7.2.04bau.

Bauer, L. (1997) 'Attempting to trace Scottish influence on New Zealand English', in Schneider, E. W. (ed.) Varieties of English Around the World. Amsterdam: John Benjamins Publishing Company, p. 257. doi: 10.1075/veaw.g19.23bau.

Bauer, L. (1999) 'On the Origins of the New Zealand English Accent', English World-Wide, 20(2), pp. 287307. doi: 10.1075/eww.20.2.05bau.

Bauer, L. et al. (2007) 'New Zealand English', Journal of the International Phonetic Association, 37(01), p. 97. doi: $10.1017 /$ S0025100306002830.

Bauer, L. (2011) Origins of NZ English. Available at: https://www.wgtn.ac.nz/lals/research/projects/grinzearchived/publications/Origins_of_NZ_English.pdf.

Bergs, A. and Brinton, L. (2017) Varieties of English. Walter de Gruyter GmbH \& Co KG.

Daly, N. (2007) 'Kükupa, Koro, and Kai : The use of Mäori vocabulary items in New Zealand English Children's Picture Books', New Zealand English Journal, pp. 20-33. 
Deverson, T. (1991) 'New Zealand English lexis: the Maori dimension', English Today, 7(2), pp. 18-25. doi: $10.1017 /$ S0266078400005496.

Gordon, E. et al. (2004) New Zealand English: its origins and evolution. Cambridge University Press.

Gordon, E. and Deverson, T. (1998) New Zealand English and English in New Zealand. New House Publishers Auckland, New Zealand.

Görlach, M. and Schneider, E. W. (1997) Englishes Around the World: Caribbean, Africa, Asia, Australasia. John Benjamins Publishing.

Harlow, R. (2007) Maori: A linguistic introduction. Cambridge University Press.

Hay, J., Maclagan, M. and Gordon, E. (2008) New Zealand English. Edinburgh: Edinburgh Univ. Press (Dialects of English).

Heggarty, P., Maguire, W. and McMahon, A. (2008) Accents of English from Around the World: Listen \& Compare Online. Available at:

http://www.lel.ed.ac.uk/research/gsound/Eng/Database/Phonetics/Englishes/Home/HomeMainFrame Holder.htm (Accessed: 24 May 2020).

Hundt, M. (2017) 'Chapter 15: Australian/New Zealand English', in Bergs, A. and Brinton, L. (eds) Varieties of English. Berlin, Boston: De Gruyter. doi: 10.1515/9783110525045-015.

Juola, P. (2006) Authorship attribution. Boston, Mass.: Now Publ (Foundations and trends in information retrieval, 1,3).

List, J.-M. et al. (2014) 'Using Phylogenetic Networks to Model Chinese Dialect History’, Language Dynamics and Change, 4(2), pp. 222-252. doi: 10.1163/22105832-00402008.

List, J.-M. (2016) 'Beyond cognacy: historical relations between words and their implication for phylogenetic reconstruction', Journal of Language Evolution, 1(2), pp. 119-136. doi: 10.1093/jole/lzw006.

List, J.-M. et al. (2018) 'Sequence comparison in computational historical linguistics', Journal of Language Evolution, 3(2), pp. 130-144. doi: 10.1093/jole/lzy006.

List, J.-M. et al. (2019) LingPy. A Python library for quantitative tasks in historical linguistics. Zenodo. doi: $10.5281 /$ zenodo.3554103.

Maguire, W. and Heggarty, P. (2019) Sound Comparisons: Englishes. Available at: https://soundcomparisons.com/\#home (Accessed: 24 May 2020).

Nelson, C. et al. (2020) The Handbook of World Englishes. 2nd edn. Wiley-Blackwell.

Swadesh, M. (2006) The origin and diversification of language. New Brunswick, (N.J.), USA: Adeline Transaction.

Trade route chart of the British Empire (1932) The British Library. The British Library. Available at: https://www.bl.uk/collection-items/trade-route-chart-of-the-british-empire (Accessed: 24 May 2020).

Trudgill, P. et al. (2000) 'Determinism in new-dialect formation and the genesis of New Zealand English', Journal of Linguistics, 36(2), pp. 299-318. doi: 10.1017/S0022226700008161.

Trudgill, P., MaClagan, M. and Lewis, G. (2003) 'Linguistic Archaeology: The Scottish Input to New Zealand English Phonology', Journal of English Linguistics, 31(2), pp. 103-124. doi: $10.1177 / 0075424203031002001$. 
Zhang, M. et al. (2019) 'Phylogenetic evidence for Sino-Tibetan origin in northern China in the Late Neolithic', Nature, 569(7754), pp. 112-115. doi: 10.1038/s41586-019-1153-z. 